\title{
Distinct Functions for Cotransmitters Mediating Motor Pattern Selection
}

\author{
Dawn M. Blitz and Michael P. Nusbaum \\ Department of Neuroscience, University of Pennsylvania School of Medicine, Philadelphia, Pennsylvania 19104-6074
}

\begin{abstract}
Motor patterns are selected from multifunctional networks by selective activation of different projection neurons, many of which contain multiple transmitters. Little is known about how any individual projection neuron uses its cotransmitters to select a motor pattern. We address this issue by using the stomatogastric ganglion (STG) of the crab Cancer borealis, which contains a neuronal network that generates multiple versions of the pyloric and gastric mill motor patterns. The functional flexibility of this network results mainly from modulatory inputs it receives from projection neurons that originate in neighboring ganglia. We demonstrated previously that the STG motor pattern selected by activation of the modulatory proctolin neuron (MPN) results from direct MPN modulation of the pyloric rhythm and indirect MPN inhibition of the gastric mill rhythm. The latter action results from MPN inhibition of projection neurons that excite the gastric mill rhythm. These projection neurons are
\end{abstract}

Rhythmically active neuronal networks generate the motor patterns underlying a wide variety of behaviors in many organisms (Marder and Calabrese, 1996; Stein et al., 1997). Many of these networks are multifunctional, producing different motor patterns in response to the activity of different modulatory inputs. Modulation of network activity has been studied via bath application of neuromodulators and by stimulation of identified modulatory neurons (Brodfuehrer et al., 1995; Marder and Calabrese, 1996; Perrins and Weiss, 1996; Sillar et al., 1997). Although immunocytochemical studies have demonstrated the presence of multiple transmitters in single network input neurons (Marder et al., 1997), there are few cases in which even the partial cotransmitter contents of identified network inputs have been characterized (Kuhlman et al., 1985a,b; Nusbaum and Kristan, 1986; Nusbaum and Marder, 1989a,b; Thorogood and Brodfuehrer, 1995; McCrohan and Croll, 1997; Blitz et al., 1999). Consequently, little is known about the contribution of individual cotransmitters toward the motor pattern resulting from the activation of particular modulatory neurons.

We have investigated how cotransmitters contribute to motor pattern selection by a modulatory projection neuron in the stomatogastric nervous system of the crab Cancer borealis. This part

Received March 17, 1999; revised May 24, 1999; accepted May 27, 1999.

This work was supported by National Science Foundation Grants IBN94-96264 and IBN98-08356 (M.P.N.) and by National Institute of Mental Health Training Grant MH-17168.

Correspondence should be addressed to Dr. Michael P. Nusbaum, 215 Stemmler Hall, Department of Neuroscience, University of Pennsylvania School of Medicine, Philadelphia, PA 19104-6074.

Dr. Blitz's present address: Department of Organismal Biology and Anatomy, University of Chicago, Chicago, IL 60637.

Copyright @ 1999 Society for Neuroscience 0270-6474/99/196774-10\$05.00/0 modulatory commissural neuron 1 (MCN1) and commissural projection neuron 2 (CPN2). MPN excitation of the pyloric rhythm is mimicked by bath application of proctolin, its peptide transmitter. Here, we show that MPN uses only its small molecule transmitter, GABA, to inhibit MCN1 and CPN2 within their ganglion of origin. We also demonstrate that MPN has no proctolin-mediated influence on MCN1 or CPN2, although exogenously applied proctolin directly excites these neurons. Thus, motor pattern selection occurs during MPN activation via proctolin actions on the STG network and GABA-mediated actions on projection neurons in the commissural ganglia, demonstrating a spatial and functional segregation of cotransmitter actions.

Key words: neuromodulation; central pattern generation; stomatogastric ganglion; proctolin; GABA; projection neurons

of the crab nervous system contains four ganglia, including the unpaired stomatogastric (STG) and oesophageal (OG) ganglia plus the paired commissural ganglia (CoGs). The influence of several projection neurons on the rhythmically active neuronal network in the crab STG has been characterized, and their transmitter contents have been determined at least partly (Nusbaum and Marder, 1989a,b; Coleman and Nusbaum, 1994; Norris et al., 1994, 1996; Bartos and Nusbaum, 1997; Blitz and Nusbaum, 1997a; Blitz et al., 1999). This knowledge of transmitter complement, plus the ability to study the function of individual identified neurons, has enabled us to determine how a particular modulatory projection neuron uses its multiple transmitters to modulate neural network activity.

Here, we focus on the projection neuron MPN and how it uses its peptide transmitter (proctolin; Nusbaum and Marder, 1989a,b) and small molecule cotransmitter (GABA; Blitz et al., 1999) to influence the pyloric and gastric mill motor patterns. These motor patterns are generated by the STG network (Harris-Warrick et al., 1992). MPN excites the pyloric rhythm by acting directly on STG network neurons (Nusbaum and Marder, 1989b), and it inhibits the gastric mill rhythm by inhibiting projection neurons within the CoGs (Blitz and Nusbaum, 1997a).

Previous work demonstrated that the MPN excitation of the pyloric rhythm within the STG is mimicked by bath-applied proctolin (Nusbaum and Marder, 1989b). We now have found that the MPN inhibition of projection neurons within the CoGs is mediated entirely by GABA. These projection neurons are responsive to direct application of proctolin but exhibit no proctolin-mediated response to MPN stimulation. Thus, motor pattern selection by MPN activity involves a segregation of cotransmitter actions. 
Some of this work has appeared previously in abstract form (Blitz and Nusbaum, 1995, 1997b).

\section{MATERIALS AND METHODS}

Animals. Crabs, Cancer borealis, were obtained from commercial suppliers (Commercial Lobster Co., Boston, MA) and the Marine Biological Laboratory (Woods Hole, MA). Animals were maintained in aerated artificial sea water at $10-12^{\circ} \mathrm{C}$ and were cold-anesthetized by being packed in ice for $20-40 \mathrm{~min}$ before dissection. The stomach, including the stomatogastric nervous system, was removed from the animal, and the rest of the dissection was performed in chilled $\left(\sim 4^{\circ} \mathrm{C}\right)$ physiological saline. Data were obtained from 109 male crabs.

Solutions. C. borealis physiological saline had the following composition (in mM): $\mathrm{NaCl}, 440 ; \mathrm{MgCl}_{2}, 26 ; \mathrm{CaCl}_{2}, 13 ; \mathrm{KCl}, 11$; Trisma base, 10; and maleic acid, 5, pH 7.4-7.6. Low $\mathrm{Ca}^{2+}$ saline had the following composition (in mM): $\mathrm{NaCl}, 440 ; \mathrm{MgCl}_{2}, 26 ; \mathrm{CaCl}_{2}, 1.3 ; \mathrm{KCl}, 11 ; \mathrm{MnCl}_{2}$, 11.7; Trisma base, 10; and maleic acid, 5, $\mathrm{pH}$ 7.4-7.6. This low $\mathrm{Ca}^{2+}$ saline eliminates transmitter release in the stomatogastric nervous system (Coleman et al., 1995; Blitz and Nusbaum, 1997a). High divalent cation saline $\left(5 \times \mathrm{Ca}^{2+} / 5 \times \mathrm{Mg}^{2+}\right)$ had the following composition (in $\left.\mathrm{mM}\right)$ : $\mathrm{NaCl}, 440 ; \mathrm{MgCl}_{2}, 130 ; \mathrm{CaCl}_{2}, 65 ; \mathrm{KCl}, 11$; Trisma base, 10 ; and maleic acid, 5, pH 7.4-7.6. This saline raises action potential threshold in the stomatogastric nervous system, thereby suppressing the spontaneous activity of many neurons and reducing the activation of polysynaptic pathways. In the CoGs this high divalent cation saline caused an overall reduction in spontaneous activity, as was evident in extracellular recordings of the output nerves (son, ion; see Fig. 1) that connect the CoGs to the STG. This included the elimination of spontaneous activity in the projection neurons MCN1 and CPN2. When the CoGs were superfused selectively with high divalent cation saline, the STG rhythms were weakened to an extent that was comparable to preparations in which the CoG output nerves were transected (Bartos and Nusbaum, 1997).

Proctolin (Sigma, St. Louis, MO) was stored as frozen aliquots $\left(10^{-2}\right.$ $\mathrm{M}$ in water) and diluted to $10^{-5} \mathrm{M}$ in crab physiological saline, low $\mathrm{Ca}^{2+}$ saline, or in picrotoxin $\left(10^{-4} \mathrm{M}\right)$ in high divalent cation saline immediately before being used. GABA (Sigma) was dissolved in low $\mathrm{Ca}^{2+}$ saline $\left(10^{-4}-10^{-3} \mathrm{M}\right)$ immediately before being used. Picrotoxin (Sigma) $\left(10^{-5}-10^{-4} \mathrm{M}\right)$ was dissolved in high divalent cation saline, low $\mathrm{Ca}^{2+}$ saline, or crab physiological saline immediately before being used.

Electrophysiology. Electrophysiological experiments were performed with standard techniques for this system (Bartos and Nusbaum, 1997; Blitz and Nusbaum, 1997a). The isolated stomatogastric nervous system (see Fig. 1) was pinned down in a silicone elastomer-lined (SYLGARD 184, KR Anderson, Santa Clara, CA) Petri dish. All preparations were superfused continuously with crab physiological saline $\left(10-13^{\circ} \mathrm{C}\right)$. In experiments in which the CoGs and STG were superfused separately, a petroleum jelly wall was built across the dish at the level of the stomatogastric nerve (stn; see Fig. 1).

Extracellular recordings were made by pressing stainless steel pin electrodes into the SYLGARD alongside the nerves and isolating each area with petroleum jelly. The desheathed ganglia were viewed with light transmitted through a dark-field condenser (Nikon, Tokyo, Japan) to facilitate intracellular recordings. Intrasomatic recordings were made by using microelectrodes (15-30 M $\Omega$ ) filled with potassium acetate (4 M) and potassium chloride $(20 \mathrm{~mm})$. Intra-axonal recordings were made by using microelectrodes (20-30 M $\Omega$ ) filled with potassium chloride (1 M) (Coleman et al., 1995). GABA was puffed into the MCN1 and CPN2 regions of the $\mathrm{CoG}$ neuropil by using microelectrodes (4-10 $\mathrm{M} \Omega$ ) connected to a Picospritzer (2-12 psi; General Valve, Fairfield, NJ). Intracellular current injection was performed with Axoclamp 2 amplifiers (Axon Instruments, Foster City, CA) in single-electrode discontinuous current-clamp (DCC) mode. Sample rates during DCC were $2-3 \mathrm{kHz}$.

STG neurons were identified on the basis of their axonal projections, their activity patterns, and their interactions with other STG neurons (Weimann et al., 1991; Norris et al., 1996; Bartos and Nusbaum, 1997). Projection neurons were identified by their axonal projection pattern and influence on the STG network (Nusbaum and Marder, 1989a,b; Coleman and Nusbaum, 1994; Norris et al., 1994; Bartos and Nusbaum, 1997; Blitz and Nusbaum, 1997a). In some experiments, CPN2 activity was monitored with a recording of the stomatogastric nerve axon (SNAX) of CPN2 at the entrance to the STG (CPN2 $\left.{ }_{\text {SNAX }}\right)$. CPN2 ${ }_{\text {SNAX }}$ was identified on the basis of its postsynaptic actions on STG network neurons (Norris et al., 1994). Data from CPN2 soma and axon recordings were pooled. In a few experiments aimed at determining whether $10^{-5} \mathrm{M}$ picrotoxin blocked the $\mathrm{MPN} \rightarrow \mathrm{CPN} 2$ synapse, CPN2 activity was monitored indirectly. This was achieved with an intracellular recording of an STG neuron, the gastric mill (GM) neuron. CPN2 is the sole source of EPSPs in GM (Norris et al., 1994; Blitz and Nusbaum, 1997a). Data collected using GM neuron recordings are indicated with the designation GM EPSPs.

Data. Data were collected on chart recorder (MT-95000, Astro-Med/ Grass Instruments, Warwick, RI) and videotape (Vetter Instruments, Rebersburg, PA). Figures were made by scanning data with an HP ScanJetIIC, using DeskScan II (Version 2.00a) software. Final figures were produced with CorelDraw (Version 3.0 for Windows).

\section{RESULTS}

\section{MPN inhibits the gastric mill rhythm}

When the stomatogastric nervous system is isolated in vitro from the remainder of the crab nervous system, the STG network regularly produces a pyloric rhythm and less frequently produces a gastric mill rhythm. This occurs during saline superfusion without any experimental intervention. There are two versions of the gastric mill rhythm that are activated most commonly under these conditions. One version is elicited by selective activity in the projection neuron $\mathrm{MCN} 1$, and the other by coactivity in MCN1 and CPN2 (Coleman and Nusbaum, 1994; Norris et al., 1994; Blitz and Nusbaum, 1997a). Intracellular stimulation of MPN excites the pyloric rhythm (Nusbaum and Marder, 1989a,b) and inhibits the aforementioned gastric mill rhythms (Fig. 1C) (Blitz and Nusbaum, 1997a). The latter action results from MPNmediated inhibition of MCN1 and CPN2 in the CoGs (Blitz and Nusbaum, 1997a). However, it had not been determined whether the MPN inhibition of MCN1 and CPN2 within the CoGs is direct. The direct targets of MPN in the CoGs needed to be identified before it was possible to evaluate the relative contributions of proctolin and GABA to the inhibitory actions of MPN on MCN1 and CPN2. We therefore began by determining whether these neurons were direct targets of MPN.

\section{MPN inhibition of MCN1 and CPN2}

MPN stimulation elicits both unitary depolarizing PSPs and a graded hyperpolarization in MCN1 and CPN2 (Fig. 2) (Blitz and Nusbaum, 1997a). The PSPs do not occur in response to every MPN action potential, nor do they occur with a fixed latency after each MPN action potential (Blitz and Nusbaum, 1997a) and therefore were not likely to be monosynaptic. The hyperpolarizing response does not consist of unitary events. To determine whether the hyperpolarizing response was likely to be direct, we superfused the CoGs with high divalent cation saline (see Materials and Methods). This saline raises action potential threshold, thus decreasing the probability of MPN activating an intervening neuron.

With the CoGs superfused with high divalent cation saline, MPN activation still consistently inhibited MCN1 $(n=12$; Fig. $2 A)$ and CPN2 $(n=6$; Fig. $2 B)$. The general time course of this inhibition also was unchanged. This included the relatively slow onset of the hyperpolarization and its prolonged duration, which outlasted MPN activity by many seconds. Note, however, that the increase in the frequency of depolarizing PSPs that occurred during MPN stimulation in normal saline was eliminated in the elevated divalent cation saline (Fig. 2).

During superfusion of the CoGs with high divalent cation saline, some tonically occurring PSPs did persist in MCN1 and CPN2 (Fig. 2). As is evident in the CPN2 recording in Figure 2, the frequency of occurrence of these PSPs was not changed by MPN stimulation. We determined that these PSPs represent synaptic input from the anterior gastric receptor neuron (AGR). 
Figure 1. Schematics of the stomatogastric nervous system, including somata location and axonal pathways of the projection neurons MPN, MCN1, and CPN2, plus a summary of MPN actions on the gastric mill rhythm. $A$, There is a pair of MPN somata located either in the $O G$ or in the nerve posterior to this ganglion. Each MPN projects an axon through each son to the $C o G$ and projects two axons through the stn to the $S T G$. It also projects an axonal branch from each son through a peripheral nerve (dpon). For clarity, the complete projection of only one MPN is shown. $B$, There is a single MCN1 and CPN2 in each CoG. Each MCN1 projects through the ion and stn to the STG. Each CPN2 projects through the son and stn to the $S T G$. For clarity, the complete projection of only one MCN1 and one CPN2 is shown. Ganglia: $C o G$, commissural ganglion; $O G$, oesophageal ganglion; $S T G$, stomatogastric ganglion. Nerves: dgn, dorsal gastric nerve; dpon, dorsal posterior oesophageal nerve; ion, inferior oesophageal nerve; lgn, lateral gastric nerve; lvn, lateral ventricular nerve; $m v n$, medial ventricular nerve; $p d n$, pyloric dilator nerve; son, superior oesophageal nerve; stn, stomatogastric nerve. Neurons: $C P N 2$, commissural projection neuron 2; $M C N 1$, modulatory commissural neuron 1 ; MPN, modulatory proctolin neuron. Anterior is toward the top, and posterior is toward the bottom. C, Left, MPN inhibits an ongoing gastric mill rhythm. Activity in MCN1 (ion) and CPN2 (monitored with an intracellular recording of the CPN2 axon as it enters the STG, CPN2 ${ }_{\text {SNAX }}$ ) elicited a gastric mill rhythm, evident from the rhythmic bursting in the $G M$ neuron and the gastric mill timed inhibition of the inferior cardiac (IC) and ventricular dilator $(V D)$ neurons $(m v n)$. MPN stimulation (between arrowheads) inhibited MCN1 and CPN2 in the CoGs, thus eliminating their excitation of the gastric mill rhythm (Modified from Blitz and Nusbaum, 1997a). C, Right, Schematic illustrating that MPN excites the pyloric rhythm directly (Nusbaum and Marder, 1989a) and inhibits the gastric mill rhythm via inhibition of MCN1 and CPN2 (Blitz and Nusbaum,

1997a). Darkened cell bodies and rhythm represent active neurons. Unfilled cell bodies and rhythm represent inactive neurons. T-junctions represent excitation, and filled circles represent inhibition.

AGR is an identified sensory neuron with a cell body and spike initiation zone posterior to the STG (Combes et al., 1993; D. M. Blitz and M. P. Nusbaum, unpublished observations). When the CoGs were superfused with high divalent cation saline, each PSP in MCN1 and CPN2 occurred with a constant latency after each AGR action potential (MCN1, $n=4$; CPN2, $n=8$ ). In our experiments the STG continued to be superfused in normal saline, and the AGR action potentials propagated into the high divalent cation saline compartment without being suppressed by this solution.

These results are consistent with MCN1 and CPN2 being direct targets of the inhibitory actions of MPN. The direct nature of these connections is reinforced by the experiments described below.

\section{Proctolin excites MCN1 and CPN2}

Nusbaum and Marder (1989b) demonstrated that the pyloric rhythm generated by MPN stimulation is reproduced by bathapplied proctolin. We wanted to determine whether proctolin application also mimicked the MPN actions on MCN1 and CPN2 in the CoGs.

MCN1 is often silent or weakly active in the isolated stomatogastric nervous system (Coleman and Nusbaum, 1994; Blitz and Nusbaum, 1997a) (Fig. 3A). Under these conditions, superfusion 


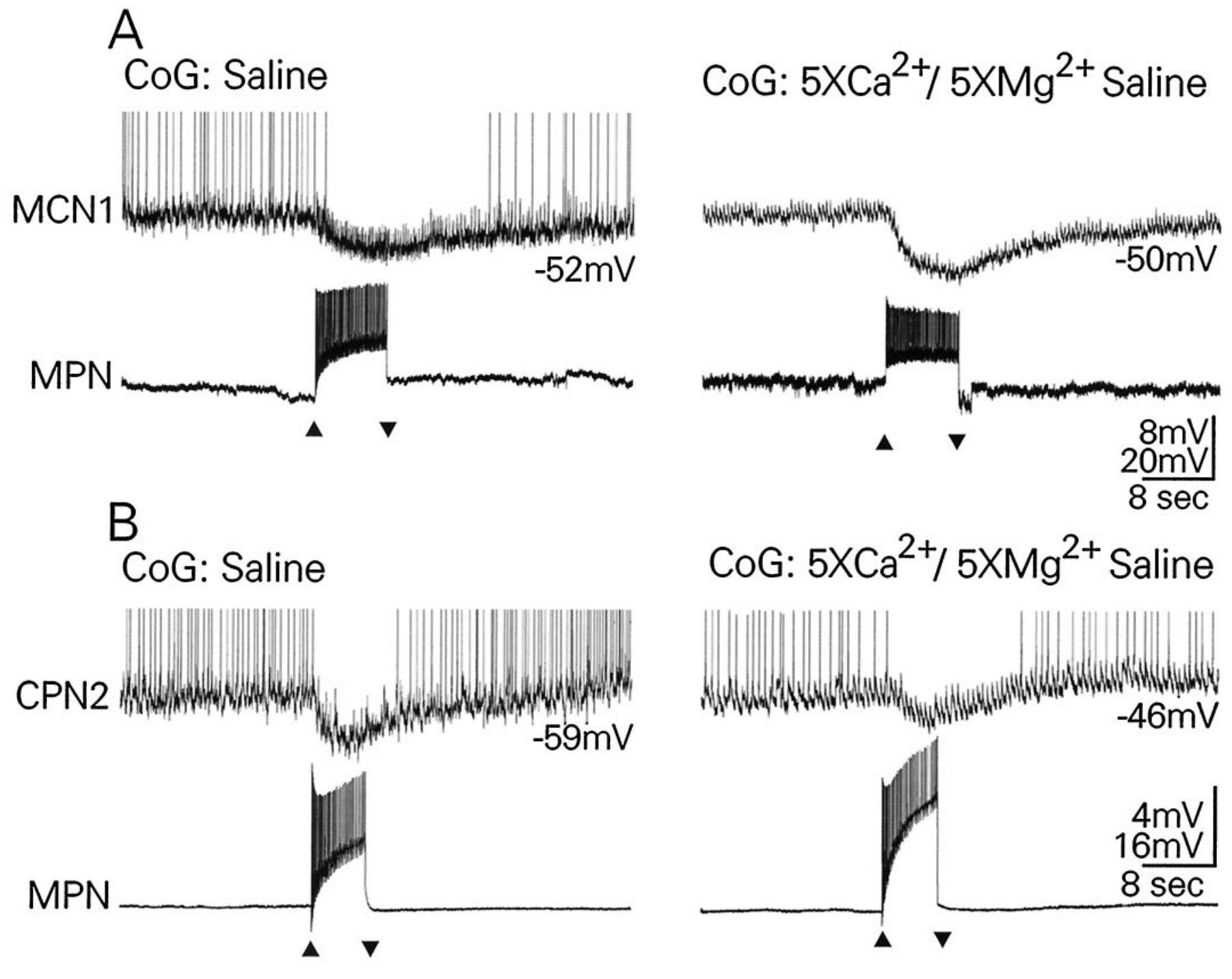

Figure 2. The MPN inhibition of MCN1 and CPN2 appears to be monosynaptic. A, Left, In normal saline MPN stimulation (13 Hz) inhibited MCN1. This inhibition produced a smooth hyperpolarization and cessation of MCN1 action potentials. Note the depolarizing PSPs in MCN1 during MPN stimulation. These PSPs were not time-locked to each MPN action potential. A, Right, Despite maintaining approximately the same membrane potential as in normal saline, MCN1 was silent during superfusion of the CoGs with high divalent cation saline. This saline raises action potential threshold. Under this condition MPN stimulation (13 Hz) still inhibited MCN1, producing a smooth hyperpolarization. The depolarizing PSPs elicited during MPN stimulation in normal saline were eliminated. The persisting EPSPs are from an identified sensory neuron, AGR (see Results), for which the spike initiation zone is outside the region superfused with high divalent cation saline. B, Left, In normal saline MPN stimulation (11 Hz) inhibited CPN2, producing a smooth hyperpolarization and cessation of CPN2 action potentials. $B$, Right, When the CoGs were superfused with high divalent cation saline, MPN stimulation ( $8 \mathrm{~Hz}$ ) still inhibited CPN2. The inhibition consisted of only a smooth hyperpolarization. The persisting PSPs are from the AGR neuron (see Results). Most hyperpolarized $V_{\mathrm{m}}$ : MPN, $-63 \mathrm{mV}$. Action potentials are clipped in MCN1 and CPN2. $A$ and $B$ are from different preparations.

of the CoGs with proctolin $\left(10^{-5} \mathrm{M}\right)$ in normal saline excited this projection neuron. The excitation included a depolarization of the MCN1 membrane potential and an increase in its firing frequency ( $n=18$ of 19 ; Fig. $3 A$ ). In three of these preparations, MCN1 was activated weakly. In the other 15 preparations MCN1 was activated strongly and fired high-frequency bursts of action potentials that were time-locked to the pyloric and gastric mill rhythms (Fig. 3A) (see below). MCN1 activity is time-locked to these rhythms because of feedback that it receives from STG network neurons (Coleman and Nusbaum, 1994).

CPN2 is often silent or weakly spontaneously active in the isolated stomatogastric nervous system (Norris et al., 1994; Blitz and Nusbaum, 1997a). Proctolin superfusion $\left(10^{-5} \mathrm{M}\right)$ of the CoGs excited CPN2 ( $n=10$; Fig. $3 A$ ). In two of 10 preparations there was a slight increase in CPN2 activity. In the other eight preparations CPN2 became rhythmically active and fired highfrequency, gastric mill rhythm-timed bursts of action potentials (Fig. 3A) (see below). CPN2 activity is time-locked to the gastric mill rhythm because of feedback that it receives from a gastric mill neuron (Norris et al., 1994). The excitatory actions of proctolin on MCN1 and CPN2 were not necessarily attributable to these neurons being direct targets of proctolin. To identify and characterize any direct proctolin actions on these projection neurons, we next applied proctolin $\left(10^{-5} \mathrm{M}\right)$ while suppressing transmitter release in the CoGs by superfusing low $\mathrm{Ca}^{2+}$ saline (see Materials and Methods). Under this condition the proctolin application still excited both MCN1 and CPN2. Specifically, with transmitter release in the CoGs eliminated, proctolin superfusion 

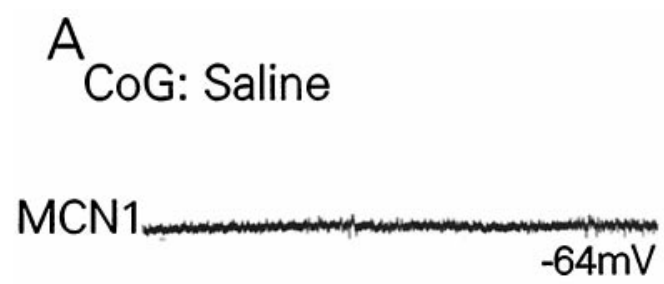

CPN2

Figure 3. Proctolin directly excites MCN1 and CPN2. $A$, In normal saline MCN1 and CPN2 were silent. Superfusion of proctolin $\left(10^{-5} \mathrm{M}\right)$ to the CoGs caused a depolarization of the membrane potential of these neurons and elicited rhythmic bursts of action potentials in them. MCN1 and CPN2 recordings are from different preparations. $B$, With transmitter release suppressed in the CoGs because of the superfusion of low $\mathrm{Ca}^{2+}$ saline, MCN1 and CPN2 were weakly active. Superfusion of proctolin $\left(10^{-5} \mathrm{M}\right)$ in this saline to the CoGs caused a depolarization of the MCN1 and CPN2 membrane potential and increased their firing frequency. $A$ and $B$ are from different preparations, as are the MCN1 and CPN2 recordings.
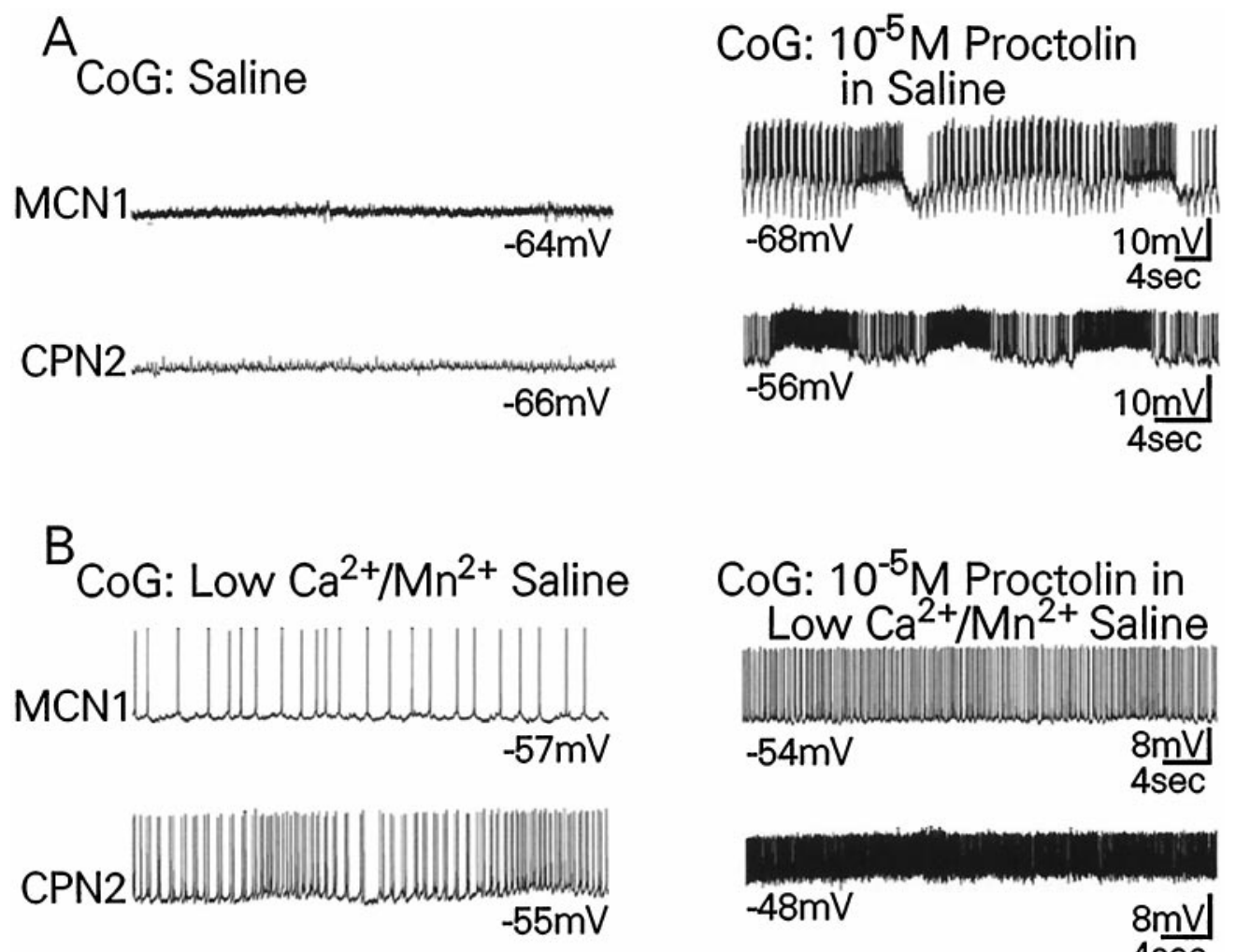
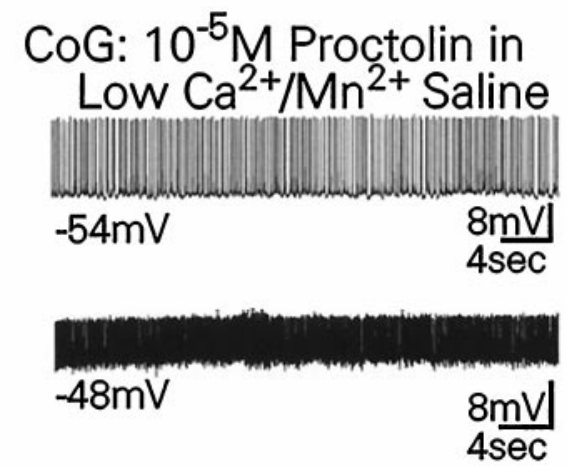

increased the firing frequency and depolarized the membrane potential of both MCN1 (Fig. $3 B ; n=5$ ) and CPN2 (Fig. $3 B ; n=$ $6)$. Note that under these conditions MCN1 and CPN2 fired tonically. This was attributable to the suppression of chemical synaptic transmission and the subsequent elimination of feedback from STG network neurons.

When proctolin application, in normal saline, was restricted to the CoGs, there was a gastric mill rhythm elicited from the STG in 15 of 21 preparations (Fig. 4). In each of these 15 preparations it was the MCN1/CPN2 version of this rhythm that was activated (see Norris et al., 1994; Blitz and Nusbaum, 1997a). Thus, as summarized in Figure $4 C$, proctolin applied to the CoGs excites MCN1 and CPN2 strongly enough for them to elicit the gastric mill rhythm from the STG network. The responses of these projection neurons to proctolin, both in normal saline and with transmitter release suppressed, were the opposite of the MPN actions on these same neurons. Thus, it did not appear that proctolin was mediating the MPN actions in the CoGs. We next examined whether these actions were mediated by GABA.

\section{GABA inhibits MCN1 and CPN2}

To determine whether GABA application mimicked the synaptic actions of MPN activity, we focally applied GABA to the CoG neuropil region of $\mathrm{MCN} 1$ and $\mathrm{CPN} 2$, where their synaptic interactions occur. We recorded intracellularly from the MCN1 or CPN2 soma while superfusing low $\mathrm{Ca}^{2+}$ saline to suppress transmitter release. We then repeatedly positioned a GABAcontaining puffer pipette $\left(10^{-4}-10^{-3} \mathrm{M}\right.$ GABA in low $\mathrm{Ca}^{2+}$ saline) into the $\mathrm{CoG}$ neuropil until we found an MCN1 and/or CPN2 GABA-responsive region. The MCN1 and CPN2 neuropil is located in the anterolateral quadrant of the CoG (Coleman and Nusbaum, 1994; Norris et al., 1994).

In low $\mathrm{Ca}^{2+}$ saline, pressure (2-12 psi; $2-8 \mathrm{sec}$ ) application of
GABA inhibited MCN1 (Fig. 5; $n=17$ ) and CPN2 (Fig. 5; $n=$ 7). This inhibition included a long-lasting hyperpolarization of the membrane potential and a cessation of action potentials in both neurons, as occurs during MPN stimulation. Superfusion of the GABA antagonist picrotoxin $\left(10^{-4} \mathrm{M}\right)$ in low $\mathrm{Ca}^{2+}$ saline reversibly suppressed the actions of focally applied GABA on MCN1 (Fig. 5; $n=9)$. Picrotoxin $\left(10^{-4} \mathrm{M}\right)$ superfusion also suppressed (Fig. $5 ; n=7$ of 11 ) or dramatically reduced $(n=4$ of 11) the actions of focally applied GABA on CPN2. In the stomatogastric nervous system this concentration of picrotoxin suppresses GABA inhibition (Marder and Paupardin-Tritsch, 1978), whereas a lower concentration of picrotoxin $\left(10^{-5} \mathrm{M}\right)$ reversibly suppresses glutamate-mediated inhibition (Marder and Paupardin-Tritsch, 1978; Golowasch and Marder, 1992b). Lower concentrations of picrotoxin also suppress glutamate-mediated inhibition, without interfering with GABA-mediated inhibition, in the crayfish swimmeret system (Sherff and Mulloney, 1996). The lower level of picrotoxin $\left(10^{-5} \mathrm{M}\right)$ did not suppress the GABA actions on MCN1 $(n=6)$ or CPN2 $(n=6)$.

Focal application of GABA in the $\mathrm{CoG}$ neuropil also mimicked the MPN-mediated suppression of the gastric mill rhythm. For example, in some preparations during superfusion of low $\mathrm{Ca}^{2+}$ saline to the CoGs, a gastric mill rhythm was elicited in the STG. This presumably resulted from the increased level of spontaneous activity in CoG projection neurons that is a consequence of suppressing ongoing levels of synaptic inhibition (Blitz and Nusbaum, 1997a). When the gastric mill rhythm was elicited under these conditions, focally applied GABA in the CoG neuropil inhibited this rhythm, concomitant with its inhibition of MCN1 and CPN2 ( $n=5$ of 5) (Fig. 6). The gastric mill rhythm did not always persist for the duration of these experiments, but when it did so, the GABA inhibition of this rhythm was eliminated by 


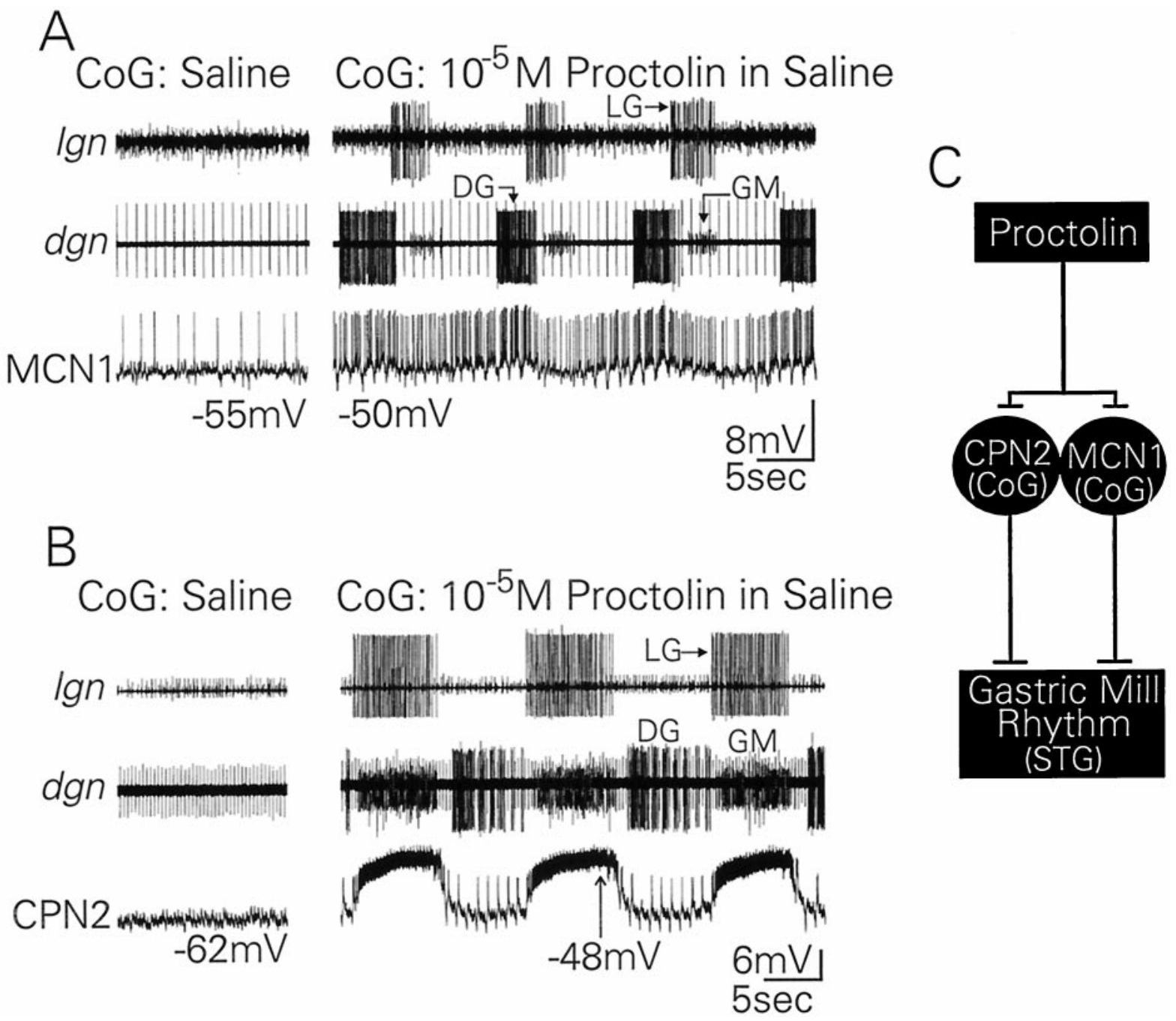

Figure 4. The proctolin excitation of $\mathrm{MCN} 1$ and $\mathrm{CPN} 2$ in the CoGs is sufficient to elicit a gastric mill rhythm from the STG. A, Left, In normal saline MCN1 was weakly active, and there was no gastric mill rhythm (note the lack of rhythmic bursting in the lgn and $d g n$ ). A, Right, Superfusion of proctolin $\left(10^{-5} \mathrm{M}\right)$ selectively to the CoGs increased the MCN1 activity and elicited a gastric mill rhythm in the STG. This rhythm includes alternating bursting in the lateral gastric (LG; $\operatorname{lgn}$ ) and dorsal gastric (DG; $d g n)$ neurons. The additional presence of the GM neuron bursts (dgn) is characteristic of the MCN1/CPN2 version of the gastric mill rhythm (Norris et al., 1994; Blitz and Nusbaum, 1997a). In C. borealis the dgn contains the axons of the DG, GM, and AGR neurons. AGR is the tonically active unit in the dgn. B, Left, In normal saline CPN2 was silent, and there was no gastric mill rhythm. $B$, Right, Superfusion of proctolin $\left(10^{-5} \mathrm{M}\right)$ selectively to the CoGs activated rhythmic CPN2 bursting that is time-locked to the elicited MCN1/CPN2 gastric mill rhythm. $C$, Summary schematic indicating that proctolin bath application to the CoGs activates MCN1 and CPN2 sufficiently for them to elicit a gastric mill rhythm from the STG network. Labeling is as in Figure 1.

picrotoxin $\left(10^{-4} \mathrm{M}\right)$ superfusion $(n=3$ of 3 ; Fig. 6$)$. Given these results, we next determined whether the MPN inhibition of MCN1 and CPN2 was sensitive to this GABA antagonist.

\section{MPN uses GABA to inhibit MCN1 and CPN2}

We tested whether picrotoxin suppressed the MPN actions on MCN1 and CPN2 in high divalent cation saline (see Fig. 2), where the potential interference of polysynaptic pathways is reduced. In this condition, picrotoxin $\left(10^{-4} \mathrm{M}\right)$ indeed reversibly eliminated the MPN inhibition of MCN1 (Fig. $7 A ; n=8$ ) and CPN2 (Fig. $7 B ; n=4$ ). Note that, whereas the MPN actions in the CoGs were suppressed by picrotoxin, MPN still excited the pyloric rhythm in the STG, which was superfused with normal saline (mvn; Fig. 7). We also applied picrotoxin at $10^{-5} \mathrm{M}$ to determine whether the actions of picrotoxin on these MPN synapses had a separable threshold from the antagonist actions on glutamatergic synapses in this system. This lower picrotoxin concentration did not interfere with the MPN inhibition of MCN1 $(n=5)$ or CPN2 $(n=2$; GM EPSPs, $n=3)$ in high divalent cation saline.

During superfusion of picrotoxin $\left(10^{-4} \mathrm{M}\right)$ in high divalent cation saline, neither MCN1 nor CPN2 exhibited any response to MPN stimulation (Fig. 7). This suggested that there was no proctolin contribution to the MPN actions on these projection neurons. There were three possible mitigating factors, however, that might have masked a proctolin action on MCN1 and CPN2 by MPN. First, it was possible that picrotoxin also interfered with the actions of proctolin. Second, the high divalent cation saline might itself have been suppressing a proctolin-mediated influence in MCN1 and CPN2. In the STG the ionic current elicited by proctolin is reduced by most divalent cations, including $\mathrm{Ca}^{2+}$, although elevated $\mathrm{Mg}^{2+}$ levels instead enhance this current (Golowasch and Marder, 1992a). To test these possibilities simultaneously, we superfused proctolin $\left(10^{-5} \mathrm{M}\right)$ to the CoGs in the presence of picrotoxin $\left(10^{-4} \mathrm{M}\right)$ in high divalent cation saline. In 


\section{CoG: Low $\mathrm{Ca}^{2+} / \mathrm{Mn}^{2+}$ Saline}

Figure 5. GABA inhibits MCN1 and CPN2 directly, and this inhibition is blocked by picrotoxin. Left, With transmitter release suppressed by low $\mathrm{Ca}^{2+}$ saline, MCN1 and CPN2 are weakly active. Pressure application of GABA in low $\mathrm{Ca}^{2+}$ saline to the MCN1 and CPN2 $\mathrm{CoG}$ neuropil caused a hyperpolarization of their membrane potentials and a cessation of action potentials. Right, When picrotoxin $\left(10^{-4} \mathrm{M}\right)$ in low $\mathrm{Ca}^{2+}$ saline was superfused to the CoGs, the same GABA puff had no influence on MCN1 or CPN2 at similar membrane potentials. MCN1 and $\mathrm{CPN} 2$ recordings are from different preparations.

Figure 6. GABA inhibition of MCN1 is sufficient to inhibit the gastric mill rhythm, and this inhibition is blocked by picrotoxin. Left, When the CoGs were superfused with low $\mathrm{Ca}^{2+}$ saline, MCN1 activity increased and a gastric mill rhythm was elicited (dgn). GABA $\left(10^{-4}\right.$ M) puffed onto the MCN1 neuropil in the CoG inhibited MCN1 and terminated the gastric mill rhythm. The rhythm resumed after the end of the puff, coincident with the resumption of MCN1 activity. Right, When picrotoxin $\left(10^{-4} \mathrm{M}\right)$ in low $\mathrm{Ca}^{2+}$ saline was superfused to the CoGs, GABA no longer had any effect on MCN1 or the gastric mill rhythm.

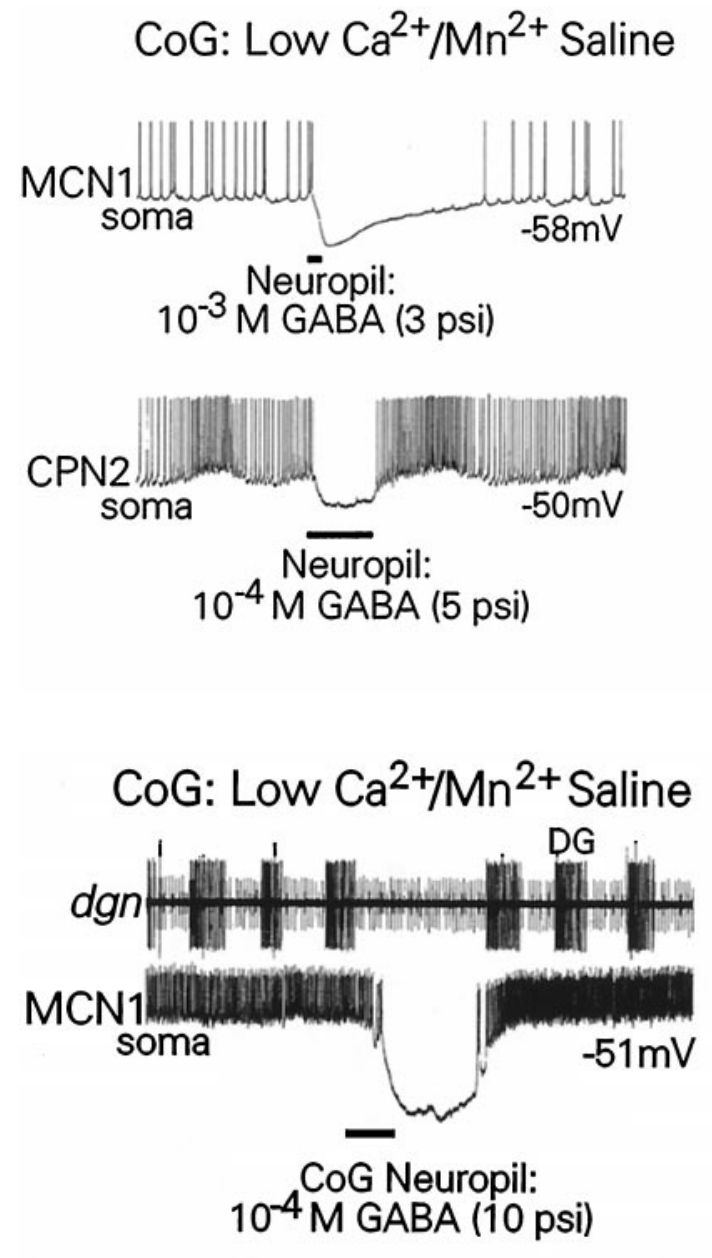

CoG: $10^{-4} \mathrm{M}$ Picrotoxin in Low $\mathrm{Ca}^{2+} / \mathrm{Mn}^{2+}$ Saline

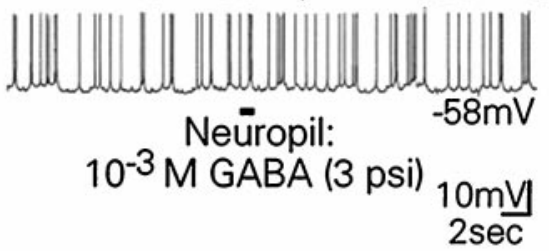

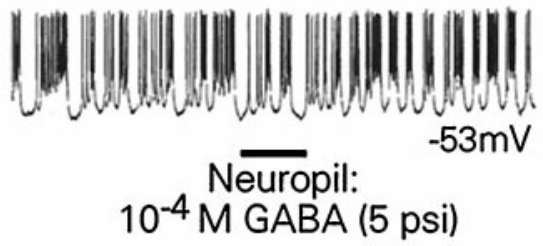

2sec

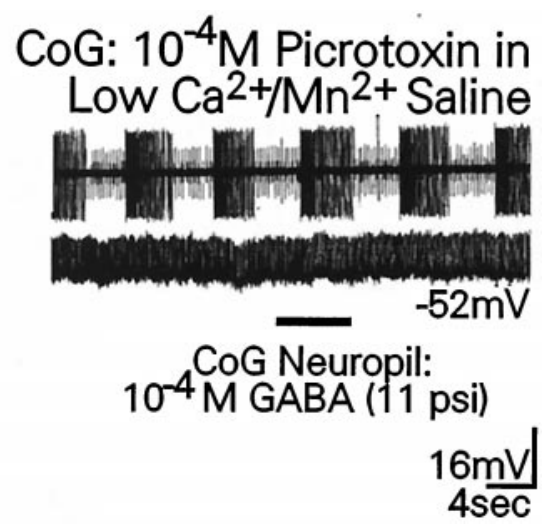

this condition, both MCN1 and CPN2 were excited consistently by proctolin application (MCN1, $n=4$; CPN2, $n=4$ ). Third, the proctolin actions in the STG are voltage-sensitive, and proctolin has little or no influence at relatively hyperpolarized potentials (Hooper and Marder, 1987; Golowasch and Marder, 1992a). Therefore, during picrotoxin $\left(10^{-4} \mathrm{M}\right)$ superfusion, we stimulated MPN while holding MCN1 and CPN2 at various membrane potentials at which proctolin effectively excites STG neurons (from -60 to $-40 \mathrm{mV}$ ). At none of these holding potentials did MCN1 or CPN2 exhibit any response to MPN stimulation (MCN1, $n=8$; CPN2, $n=3$ ).

We also determined whether the MPN inhibition of the gastric mill rhythm was sensitive to the GABA antagonist. Superfusion of $10^{-5} \mathrm{M}$ picrotoxin to the CoGs eliminates glutamatergic inhibition and increases the activity of MCN1 and CPN2 (D. M. Blitz and M. P. Nusbaum, unpublished observations). We used this method of increasing MCN1 and CPN2 activity to elicit a gastric mill rhythm (Fig. 8). In the presence of this concentration of picrotoxin, MPN stimulation still inhibited the gastric mill rhythm (Fig. 8; $n=6$ ). However, superfusion of the CoGs with $10^{-4} \mathrm{M}$ picrotoxin, which blocks GABA synapses, reversibly eliminated the MPN inhibition of this gastric mill activity (Fig. $8 ; n=6$ ).

\section{DISCUSSION}

We have found that a modulatory projection neuron uses predominantly its peptide transmitter to influence one rhythmic motor pattern, whereas it uses exclusively its small molecule transmitter to influence a related but distinct motor rhythm. These distinct actions of the MPN cotransmitters on the pyloric circuit in the STG and on identified projection neurons in the CoGs combine to produce a specific STG motor pattern (Fig. 9).

Bath application of neuromodulators commonly is used to study the modulation of network activity (Kiehn and Kjærulff, 1996; Marder, 1997; McCormick and Bal, 1997; Sillar et al., 1997; Parker and Grillner, 1998). These studies have provided considerable information about how modulatory transmitters can reshape neural network activity to produce multiple neural activity patterns. However, in few cases has it been possible to determine how well bath application mimics a neuronal network response to neurally released transmitter(s) (Kuhlman et al., 1985a,b; Nusbaum and Kristan, 1986; Acevedo et al., 1994; McCrohan and Croll, 1997). Here, we show that bath-applied proctolin and MPN stimulation have opposite actions on MCN1 and CPN2 in the CoGs, although bath-applied proctolin does mimic the MPN actions in the STG (Nusbaum and Marder, 1989b). This demonstrates some of the problems that can arise in using bath application studies to understand the neuronal modulation of neural network activity. Bath application studies remain a valuable tool for examining the modulation of cellular and synaptic properties (Calabrese and Feldman, 1997; McCormick and Bal, 1997; McDearmid et al., 1997; Weimann et al., 1997; Ayali et al., 1998). However, our study indicates that caution should be exercised in relating the anticipated actions of a particular modulatory neuron 


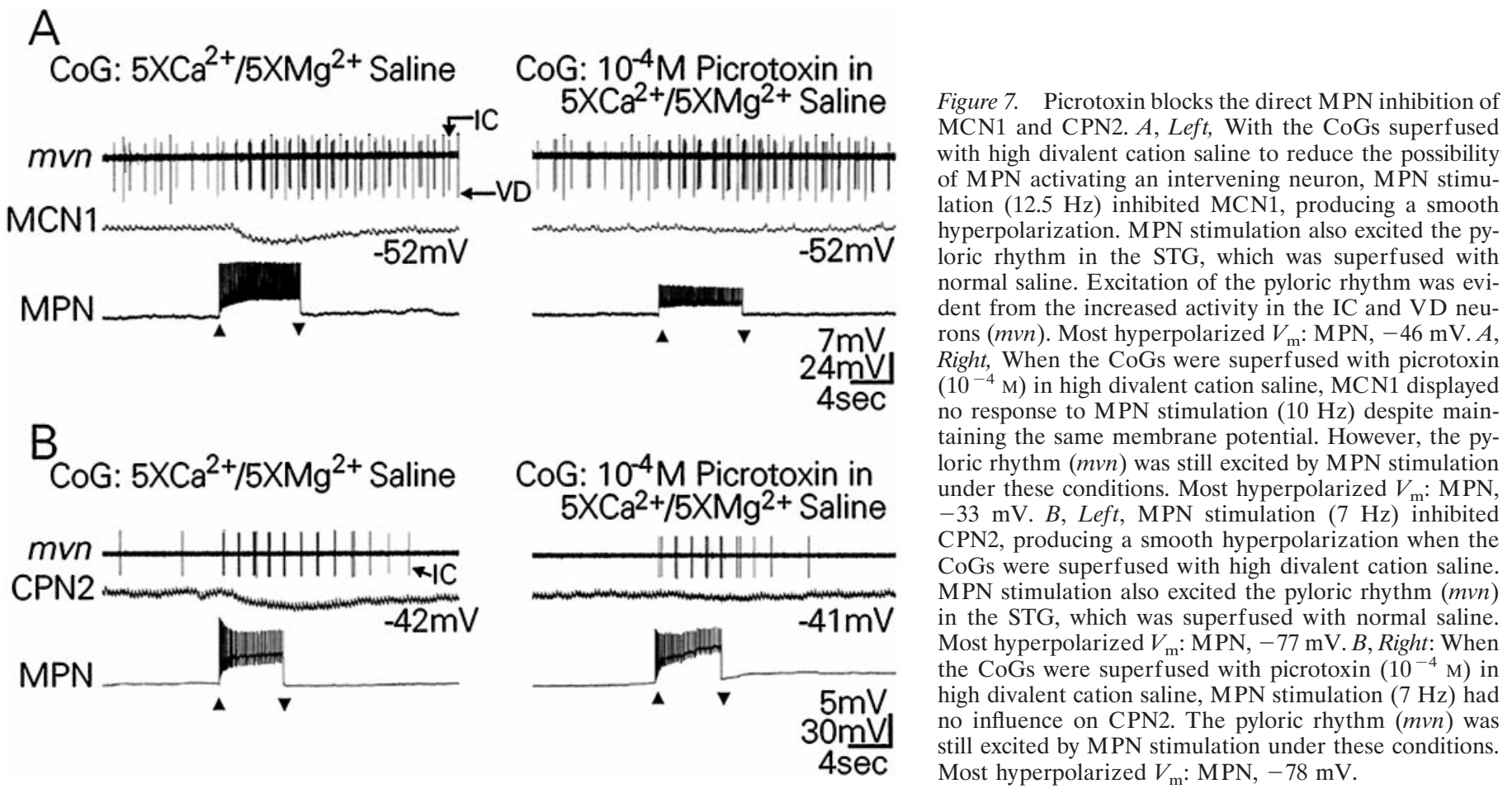

or neuronal population to the neural network responses to bathapplied neuromodulators.

We do not know the circumstance under which MCN1 and CPN2 might receive proctolinergic input and whether this input indeed would mimic what we have found with our proctolin bath application experiments. However, the CoGs contain an extensive proctolin immunoreactive neuropil as well as several immunoreactive somata (Marder et al., 1986). In fact, MCN1 itself is proctolin immunoreactive (Blitz et al., 1999), and MCN1 stimulation can recruit $\mathrm{CPN} 2$ to produce the $\mathrm{MCN} 1 / \mathrm{CPN} 2$ gastric mill rhythm (D. M. Blitz and M. P. Nusbaum, unpublished observations). Thus, perhaps MCN1 is an endogenous source of proctolin excitation to CPN2.

It remains uncertain whether GABA is used by MPN in the STG. However, we have now documented a role for GABA as an MPN transmitter in the CoGs. GABA mediates the MPN inhibition of MCN1 and CPN2 within the CoGs, thereby suppressing the gastric mill rhythm in the STG. Thus, the predominant functions of the MPN cotransmitters appear to be segregated both by the rhythm that they target as well as by the spatial location of their target neurons.

MPN appears to contain proctolin and GABA in the STG, because its axon in the stomatogastric nerve exhibits both proctolin and GABA immunoreactivity (A. E. Christie, D. M. Blitz, and M. P. Nusbaum, unpublished observations). Although we have documented that MPN has GABAergic actions in the CoGs, we do not yet know if MPN contains proctolin within its CoG arbor. The lack of a proctolin-mediated action by MPN on MCN1 and CPN2 may result from MPN releasing proctolin into the CoG neuropil, but MPN-released proctolin not having access to the proctolin receptors on these projection neurons. Although neurally released peptides can diffuse considerable distances to their receptors (Jan et al., 1980; Hokfelt, 1991; Zupanc, 1996), neurally released proctolin may be restricted spatially. There is, for example, extracellular peptidase activity that cleaves and inactivates proctolin in the crab nervous system (Coleman et al.,

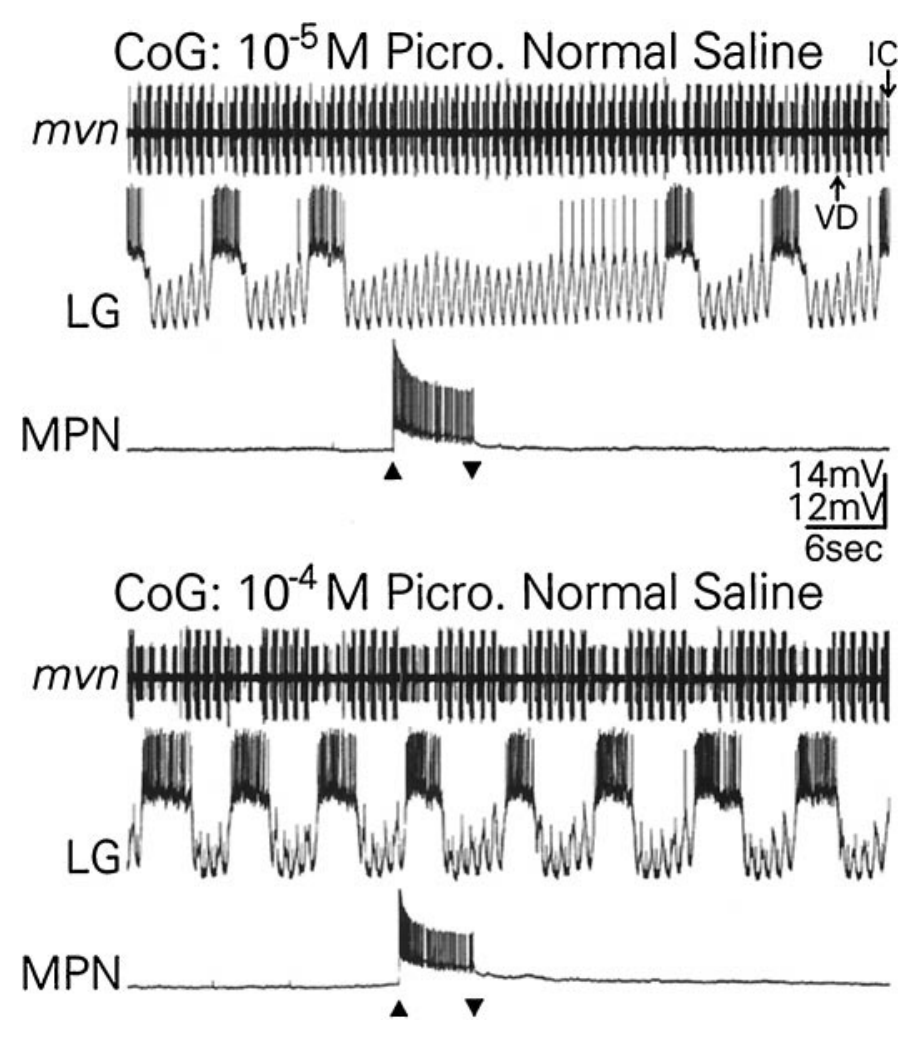

Figure 8. MPN inhibition of the gastric mill rhythm is blocked by $10^{-4}$ M picrotoxin, but not by $10^{-5} \mathrm{M}$ picrotoxin. Top, Superfusion of the CoGs with $10^{-5} \mathrm{M}$ picrotoxin in normal saline increased the activity of MCN1 and CPN2 (data not shown) and elicited gastric mill timed bursting in the LG neuron. MPN stimulation $(13 \mathrm{~Hz})$ terminated the gastric mill timed bursting in the LG neuron and the gastric mill timed inhibition of the VD neuron (mvn). Bottom, When the CoGs were superfused with $10^{-4} \mathrm{M}$ picrotoxin in normal saline, MPN stimulation $(13 \mathrm{~Hz})$ had no influence on the gastric mill rhythm. Most hyperpolarized $V_{\mathrm{m}}$ : LG, $-68 \mathrm{mV}$; MPN, $-74 \mathrm{mV}$. Scale bars are for top and bottom. 


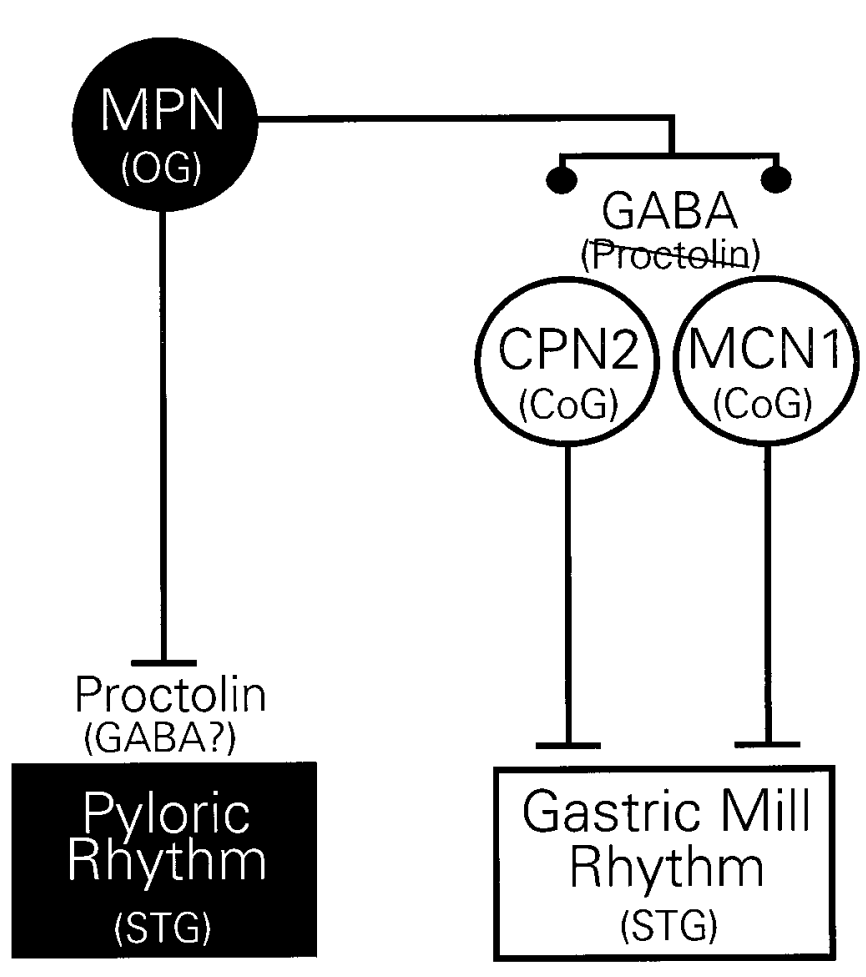

Figure 9. Schematic of the roles of the MPN transmitters in mediating selection of the MPN-elicited motor pattern. MPN uses proctolin to excite the pyloric rhythm within the STG (Nusbaum and Marder, 1989b). The role of GABA in the STG is unknown. MPN uses GABA in the CoGs to inhibit MCN1 and CPN2, removing their excitation of the gastric mill rhythm. MPN does not have a proctolin-mediated influence on these neurons. Labels are as in Figure 1.

1994; Nusbaum and Wood, 1999). Alternatively, MPN may not contain proctolin in its CoG terminals. If MPN either does not release proctolin from all of its CoG terminals or contains no proctolin within the $\mathrm{CoG}$, then this would contradict a longstanding principle in neuroscience known as Dale's principle. Dale's principle originated before the knowledge of cotransmitters. However, in its modernized form it dictates that all transmitters of a neuron are contained within and released from all of its terminals (Dale, 1935; Eccles, 1986). It has been daunting to support or reject Dale's principle in any system because of the difficulty of determining the transmitter content of individual neurons at all of their terminals. There is one example of anatomical segregation of cotransmitters, within the Aplysia bag cells. In these neurons there is differential transport of two peptides to spatially separate arbors (Sossin et al., 1990).

The modulation of network neuron membrane and synaptic properties underlies the functional flexibility of neural networks (Marder and Calabrese, 1996; Stein et al., 1997). In addition to these direct actions on network neurons, motor pattern selection from multifunctional networks can occur in part via indirect actions such as those occurring among parallel network inputs (Brodfuehrer and Burns, 1995; Faumont et al., 1996; Blitz and Nusbaum, 1997a). This study demonstrates that these direct and indirect actions on network activity can be mediated by different transmitters of a single modulatory neuron. Future work aimed at understanding how network inputs select their distinct motor patterns will certainly require a greater understanding of the roles of cotransmitters.

\section{REFERENCES}

Acevedo LD, Hall WM, Mulloney B (1994) Proctolin and excitation of the crayfish swimmeret system. J Comp Neurol 345:612-627.

Ayali A, Johnson BR, Harris-Warrick RM (1998) Dopamine modulates graded and spike-evoked synaptic inhibition independently at single synapses in pyloric network of lobster. J Neurophysiol 79:2063-2069.

Bartos M, Nusbaum MP (1997) Intercircuit control of motor pattern modulation by presynaptic inhibition. J Neurosci 17:2247-2256.

Blitz DM, Nusbaum MP (1995) Neuropeptide activation of rhythmic motor activity via excitation of identified projection neurons. Soc Neurosci Abstr 21:629.

Blitz DM, Nusbaum MP (1997a) Motor pattern selection via inhibition of parallel pathways. J Neurosci 17:4965-4975.

Blitz DM, Nusbaum MP (1997b) Distinct functions for cotransmitters mediating motor pattern selection by a modulatory projection neuron. Soc Neurosci Abstr 23:117.

Blitz DM, Christie AE, Coleman MJ, Norris BJ, Marder E, Nusbaum MP (1999) Different proctolin neurons elicit distinct motor patterns from a multif unctional neuronal network. J Neurosci 19:5449-5463.

Brodfuehrer PD, Burns A (1995) Neuronal factors influencing the decision to swim in the medicinal leech. Neurobiol Learn Mem 63:192-199.

Brodfuehrer PD, Parker HJ, Burns A, Berg M (1995) Regulation of the segmental swim-generating system by a pair of identified interneurons in the leech head ganglion. J Neurophysiol 73:983-992.

Calabrese RL, Feldman JL (1997) Intrinsic membrane properties and synaptic mechanisms in motor rhythm generators. In: Neurons, networks, and motor behavior (Stein PSG, Grillner S, Selverston AI, Stuart DG, eds), pp 119-130. Cambridge, MA: MIT.

Coleman MJ, Nusbaum MP (1994) Functional consequences of compartmentalization of synaptic input. J Neurosci 14:6544-6552.

Coleman MJ, Konstant PH, Rothman BS, Nusbaum MP (1994) Neuropeptide degradation produces functional inactivation in the crustacean nervous system. J Neurosci 14:6205-6216.

Coleman MJ, Meyrand P, Nusbaum MP (1995) A switch between two modes of synaptic transmission mediated by presynaptic inhibition. Nature 378:502-505.

Combes D, Simmers J, Nonnotte L, Moulins M (1993) Tetrodotoxinsensitive dendritic spiking and control of axonal firing in a lobster mechanoreceptor neurone. J Physiol (Lond) 460:581-602.

Dale HH (1935) Pharmacology and nerve endings. Proc R Soc Med 28:319-332.

Eccles JC (1986) Chemical transmission and Dale's principle. Prog Brain Res 68:3-13.

Faumont S, Simmers J, Meyrand P (1996) Stabilizing control of a motor pattern generating network via interacting higher order modulatory interneurons. Soc Neurosci Abstr 22:132.

Golowasch J, Marder E (1992a) Proctolin activates an inward current whose voltage dependence is modified by extracellular $\mathrm{Ca}^{2+}$. J Neurosci 12:810-817.

Golowasch J, Marder E (1992b) Ionic currents of the lateral pyloric neuron of the stomatogastric ganglion of the crab. J Neurophysiol 67:318-331.

Harris-Warrick RM, Marder E, Selverston A, Moulins M (1992) Dynamic biological networks: the stomatogastric nervous system. Cambridge, MA: MIT.

Hokfelt T (1991) Neuropeptides in perspective: the last ten years. Neuron $7: 867-879$.

Hooper SL, Marder E (1987) Modulation of the lobster pyloric rhythm by the peptide proctolin. J Neurosci 7:2097-2112.

Jan LY, Jan YN, Brownfield MS (1980) Peptidergic transmitters in synaptic boutons of sympathetic ganglia. Nature 288:380-382.

Kiehn O, Kjærulff O (1996) Spatiotemporal characteristics of 5-HT and dopamine-induced rhythmic hindlimb activity in the in vitro neonatal rat. J Neurophysiol 75:1472-1482.

Kuhlman JR, Li C, Calabrese RL (1985a) FMRF-amide-like substances in the leech. I. Immunocytochemical localization. J Neurosci 5:2301-2309.

Kuhlman JR, Li C, Calabrese RL (1985b) FMRF-amide-like substances in the leech. II. Bioactivity on the heartbeat system. J Neurosci 5:2310-2317.

Marder E (1997) Computational dynamics in rhythmic neural circuits. Neuroscientist 3:295-302.

Marder E, Calabrese RL (1996) Principles of rhythmic motor pattern generation. Physiol Rev 76:687-717.

Marder E, Paupardin-Tritsch D (1978) The pharmacological properties 
of some crustacean neuronal acetylcholine, $\gamma$-aminobutyric acid, and L-glutamate responses. J Physiol (Lond) 280:213-236.

Marder E, Hooper SL, Siwicki KK (1986) Modulatory action and distribution of the neuropeptide proctolin in the crustacean stomatogastric nervous system. J Comp Neurol 243:454-467.

Marder E, Jorge-Rivera JC, Kilman V, Weimann JM (1997) Peptidergic modulation of synaptic transmission in a rhythmic motor system. Adv Org Biol 2:213-233.

McCormick DA, Bal T (1997) Sleep and arousal: thalamocortical mechanisms. Annu Rev Neurosci 20:185-215.

McCrohan CR, Croll RP (1997) Characterization of an identified cerebrobuccal neuron containing the neuropeptide APGWamide (Ala-ProGly-Trp- $\mathrm{NH}_{2}$ ) in the snail Lymnaea stagnalis. Invert Neurosci 2:273-283.

McDearmid JR, Scrymgeour-Wedderburn JF, Sillar KT (1997) Aminergic modulation of glycine release in a spinal network controlling swimming in Xenopus laevis. J Physiol (Lond) 503:111-117.

Norris BJ, Coleman MJ, Nusbaum MP (1994) Recruitment of a projection neuron determines gastric mill motor pattern selection in the stomatogastric nervous system of the crab, Cancer borealis. J Neurophysiol 72:1451-1463.

Norris BJ, Coleman MJ, Nusbaum MP (1996) Pyloric motor pattern modification by a newly identified projection neuron in the crab stomatogastric nervous system. J Neurophysiol 75:97-108.

Nusbaum MP, Kristan Jr WB (1986) Swim initiation in the leech by serotonin-containing interneurons, cells 21 and 61. J Exp Biol 122:277-302.

Nusbaum MP, Marder E (1989a) A modulatory proctolin-containing neuron (MPN). I. Identification and characterization. J Neurosci 9:1591-1599.

Nusbaum MP, Marder E (1989b) A modulatory proctolin-containing neuron (MPN). II. State-dependent modulation of rhythmic motor activity. J Neurosci 9:1600-1607.

Nusbaum MP, Wood DE (1999) The role of co-transmitters and pepti- dase activity in shaping the actions of peptidergic neurons. Soc Neurosci Abstr, in press.

Parker D, Grillner S (1998) Cellular and synaptic modulation underlying substance P-mediated plasticity of the lamprey locomotor network. J Neurosci 18:8095-8110.

Perrins R, Weiss KR (1996) A cerebral central pattern generator in Aplysia and its connections with buccal feeding circuitry. J Neurosci 16:7030-7045.

Sherff CM, Mulloney B (1996) Tests of the motor neuron model of the local pattern-generating circuits in the swimmeret system. J Neurosci 16:2839-2859.

Sillar KT, Kiehn O, Kudo N (1997) Chemical modulation of vertebrate motor circuits. In: Neurons, networks, and motor behavior (Stein PSG, Grillner S, Selverston AI, Stuart DG, eds), pp 183-193. Cambridge, MA: MIT.

Sossin WS, Sweet-Cordero A, Scheller RH (1990) Dale's hypothesis revisited: different neuropeptides derived from a common prohormone are targeted to different processes. Proc Natl Acad Sci USA 87:4845-4848.

Stein PSG, Grillner S, Selverston AI, Stuart DG (1997) Neurons, networks, and motor behavior. Cambridge, MA: MIT.

Thorogood MSE, Brodfuehrer PD (1995) The role of glutamate in swim initiation in the medicinal leech. Invert Neurosci 1:223-233.

Weimann JM, Meyrand P, Marder E (1991) Neurons that form multiple pattern generators: identification and multiple activity patterns of gastric/pyloric neurons in the crab stomatogastric system. J Neurophysiol 65:111-112.

Weimann JM, Skiebe P, Heinzel HG, Soto C, Kopell N, Jorge-Rivera JC, Marder E (1997) Modulation of oscillator interactions in the crab stomatogastric ganglion by crustacean cardioactive peptide. J Neurosci 17:1748-1760.

Zupanc GKH (1996) Peptidergic transmission: from morphological correlates to functional implications. Micron 27:35-91. 